\title{
Role of T- and B-lymphocytes in pulmonary host defences
}

\author{
B.B. Moore, T.A. Moore, G.B. Toews
}

Role of T- and B-lymphocytes in pulmonary host defences. B. B. Moore, T.A. Moore, G.B. Toews. CERS Journals Ltd 2001.

ABSTRACT: Pulmonary infectious diseases cause significant morbidity and mortality in both industrialized and developing countries.

Adaptive immune responses are required to defend the lung against pathogens that survive in normal macrophages and extracellular organisms that evade phagocytosis. Microbes initiate both innate immune responses and specific adaptive immune responses.

Innate immune response molecules regulate T-lymphocyte differentiation. Activated T-lymphocytes provide cytokines, which activate macrophages and lytic signals that lyse infected antigen-presenting cells.

Antibodies produced by plasma cells facilitate microbial clearance through diverse effector mechanisms including opsonization, complement fixation and antibodydependent cytotoxicity. Lymphocytes determine the specificity of the immune response and orchestrate effector limbs of the immune response. Eur Respir J 2001; 18: 846-856.
Dept of Internal Medicine, Division of Pulmonary and Critical Care Medicine, University of Michigan Medica Center, Ann Arbor, Michigan, USA.

Correspondence: G.B. Toews, University of Michigan School of Medicine, 6301 MSRB III, $1150 \mathrm{~W}$. Medical Center Drive, Ann Arbor, MI 48109-0642, USA.

Fax: 17347644556

Keywords: Antibodies, immunology, lymphocytes, pulmonary host defences

Received: March 222001

Accepted after revision May 82001

This research was supported in part by a Research Grant from the American Lung Association and a Parker B. Francis Fellowship Award (T.A Moore) and grants CA79046 (B.B Moore), HL51082 (G.B. Toews), P50HL56402 (G.B. Toews and B.B. Moore), and HL60289 (G.B. Toews, B.B. Moore and T.A. Moore) from the National Institutes of Health. In addition, G.B. Toews is supported by a Merit Review grant from the Veteran's Administration.
Pulmonary infectious diseases remain a major healthcare burden in both industrialized and developing countries. Tuberculosis alone is responsible for 1.5 million deaths per year worldwide. The pulmonary immune system provides a means to generate highly specific, rapid, protective responses against pathogenic microbes. Lymphocytes occupy centre stage in the immune system because they determine the specificity of the immune response and orchestrate the effector limbs of the immune response.

Specific pulmonary immune responses are particularly important to defend the lung against pathogens that survive in normal macrophages (mycobacteria, fungi, viruses) and extracellular organisms that successfully evade phagocytosis (virulent encapsulated bacteria, fungi). Microbial infections that evade the innate defense mechanisms and inflammatory responses generate threshold doses of antigen (Ag), which trigger Ag-specific immune responses. Ag-specific immune responses involve the proliferation and differentiation of Ag-specific T- and B-lymphocytes.

\section{Regulation of T-cell subset development}

T-cell subsets have discrete patterns of cytokine production

Subsets of both CD4 and CD8 T-cells can be distinguished according to their ability to produce discrete patterns of cytokines (fig. 1) [1, 2]. The characterization of $\mathrm{T}$-cell responses as belonging to

Previous articles in this series: No. 1: Pilette C, Ouadrhiri Y, Godding V, Vaerman J-P, Sibille Y. Lung mucosal immunity: immunglobulin-A revisited. Eur Respir J 2001; 18: 571-588. No. 2: Lambrecht BN, Prins J-B, Hoogsteden HC. Lung dendritic cells and host immunity to infection. Eur Respir J 2001; 18: 692-704. 


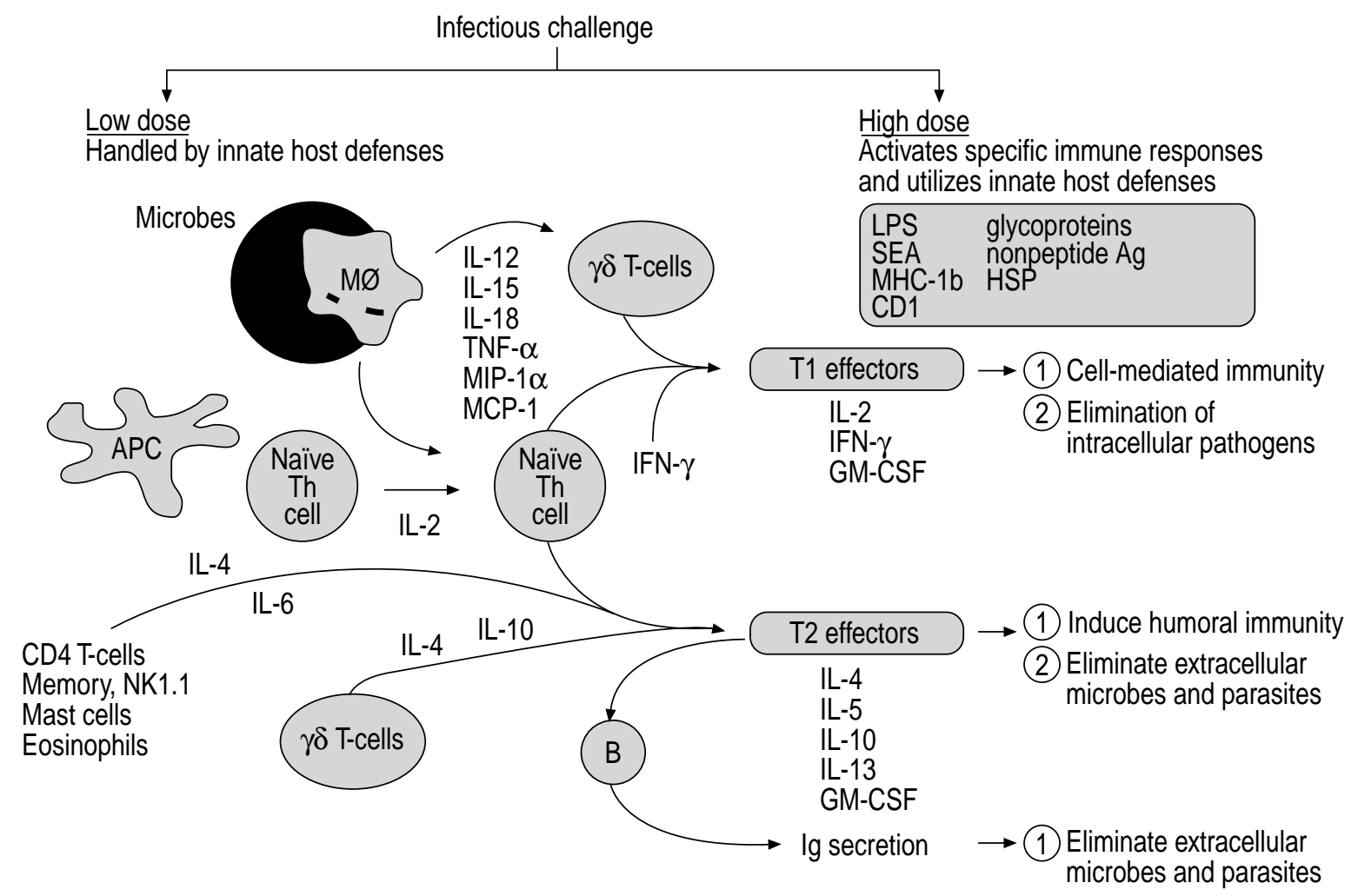

Fig. 1.-Regulation of pulmonary immune responses. Infectious agents initiate both innate defence mechanisms and specific T- and B-lymphocyte responses. Innate immune responses provide crucial molecules, which regulate T-lymphocyte subset differentiation. Cytokine products of activated T-lymphocytes provide crucial macrophage activating signals and drive the development of humoral immunity. Membrane-bound ligands on activated T-lymphocytes provide important lytic signals to infected antigen (Ag)-presenting cells. Antibodies (Abs) produced by activated B-lymphocytes facilitate clearance of the pathogen through a variety of effector mechanisms, including complement fixation, Ab-dependent cellular cytotoxicity, and opsonization. NK: natural killer; SEA: staphylococcal enterotoxinA; HSP: heat shock protein; APC: Ag-presenting cells; Th: T-helper; IL: interleukin; TNF- $\alpha$ : tumour necrosis factor- $\alpha$; MIP-1 $\alpha$ : macrophage inflammatory protein-1 $\alpha$; MCP-1: monocyte chemotactic peptide-1; IFN- $\gamma$ : interferon- $\gamma$; LPS: lipopolysaccharide; MHC: major histocompatibility complex; GM-CSF: granulocyte macrophage colony stimulating factor; Ig: immunoglobulin.

either T1-type responses (dominated by interferon- $\gamma$ $(\mathrm{IFN}-\gamma)$ production and associated with cell-mediated immunity) or T2-type responses (characterized by interleukin (IL)-4 and IL-5 production and associated with humoral immunity) is important because it provides a basis for understanding how T-cells contribute to resistance and/or susceptibility to different infections. The development of these distinct T-cell subsets is strongly dictated by the type of $\mathrm{Ag} /$ microbe invading a host, the genetic background of the host, and the dose and route of immunization. Early events in an immune response stimulate the production of cytokines that direct the subsequent development of T-cell subsets with discrete patterns of cytokine production.

$\mathrm{T}$-cells that produce both $\mathrm{T} 1$ and $\mathrm{T} 2$ cytokines (termed T0) have been described in humans and mice. Whether T0 cells are precursors for T1 and T2 cells or represent a separate, stable, differentiated population remains unclear. T0 cells may be involved in eliminating pathogens, particularly those where a balance between cell-mediated immunity and an appropriate humoral response is ideal for eradication of an invading pathogen.

T1 cells produce IL- 2 , IFN- $\gamma$, granulocyte macrophage colony stimulating factor (GM-CSF), and tumour necrosis factor- $\beta$ (TNF- $\beta$, lymphotoxin). T2 cells produce IL-4, IL-5, IL-6, IL-10, and IL-13. These two lymphocyte subsets differ in function. T1 cells enhance the microbicidal activity of monocytes and macrophages and increase their efficiency in lysing micro-organisms in intracellular vesicular compartments. T2 cells provide help for antibody (Ab) responses and induce immunoglobulin (Ig)-G1, IgA, and IgE.

Cytokine secretion is not limited to CD4 cells. Analogous, but not identical, populations of T1 and T2 CD8 lymphocytes can be generated in vitro under conditions very similar to those used for generating CD4 T-lymphocyte subsets. CD8 T-lymphocytes have been classified into three classes: 1) traditional CD8+ T-lymphocytes that make IFN- $\gamma$; 2) CD8+ cytotoxic T-lymphocytes that make IL-4, IL-5 and IL-10; and 3) noncytotoxic cells that lose CD8 positivity and make IL-4, IL-5 and IL-10. The reciprocal interactions between $\mathrm{T} 1$ and $\mathrm{T} 2$ cytokine production by CD8 cells parallels CD4+ T-lymphocyte differentiation. Polarized CD8+ cells are not just an in vitro phenomenon. CD8 T-lymphocytes have been shown to be of importance for disease resolution in hosts infected with viruses, Toxoplasma gondii, Listeria monocytogenes, Leishmania major, Cryptococcus neoformans, and mycobacteria. 
Innate immune cells play a crucial role in the development of T1 cells

Following the ingestion of microbes, macrophages and dendritic cells produce IL-12 [3, 4]. IL-12 powerfully induces the development of T1 cells following the interaction of naïve CD4 cells with Ag-bearing dendritic cells. IL-12 is also a powerful inducer of IFN- $\gamma$ secretion by natural killer (NK) cells. IFN- $\gamma$ is a powerful promoter of the development of $\mathrm{T} 1$ cells. Cytokines secreted by lymphocytes also control the development of T1 cells. IFN- $\gamma$, produced by T1 cells, suppresses the development of T2 cells, whereas conversely, IL-10 and IL-4, produced by T2 cells, suppress the development of T1 cells.

The role of interleukin-12 and interleukin-18 in $T 1$ differentiation

Naïve CD4 T-cells develop into T1 cells in response to IL-12 with the participation of other cofactors, such as IL-1 $\alpha$ and IL-18. T1 development is also dependent on IFN- $\gamma$ and maintenance of this phenotype depends on stimulation in the presence of IL-12 and IL-18. IL-4 directly antagonizes T1 responses, and IL-10 indirectly inhibits these responses by inhibiting the production of inflammatory mediators, such as IL-12 and IL-18 by macrophages (fig. 1).

IL-12 is a $75 \mathrm{kDa}$ heterodimer, which is produced by macrophages when they encounter many microbial products, including lipopolysaccharides, components of viruses, intracellular bacteria, fungi and protozoa. Dendritic cells also produce IL-12 under certain conditions including ligation of CD40 by CD40L and/or major histocompatibility complex (MHC) class II ligation. IL-12 directs T1 development from Ag-stimulated naïve T-cells and activates Stat3 and Stat 4 in T1 cells. Gene deletion of IL-12 or Stat4 markedly reduces $\mathrm{T} 1$ responses, demonstrating that IL-12 signalling through these pathways is required in vivo. Functional receptors for IL-12 appear to be restricted to recently activated, uncommitted cells and to T1 cells; functional receptors for IL-12 are lost during the development of T2 cells. T1 development is also dependent on IFN- $\gamma$. The effects of IFN- $\gamma$ may be mediated via its action on the macrophage to upregulate IL-12 production or by direct effects on the T-cell. The molecular basis of IL-12 responsiveness is dependent upon the expression of $\operatorname{IL}-12 \mathrm{R}[5,6]$. IL-4 downregulates expression of IL-12R $\beta_{2}$, whereas IFN- $\gamma$ upregulates expression [7].

IL-18, a member of the IL-1 family, also has an important role in $\mathrm{T} 1$ development. This cytokine promotes proliferation and IFN- $\gamma$ production by $\mathrm{T} 1$ clones and lines as well as NK cells. IL-18 does not drive T1 development, but rather potentiates IL-12induced T1 development. IL-18 does not activate Stat 4 in T1 cells but signals through the interleukin-1 receptor associated kinase pathway $[6,8]$.

The role of IL-18 in protective $\mathrm{T} 1$ responses remains uncertain, but is suggested by three findings: 1) IL-18 synergizes with IL-12 to enhance production of IFN- $\gamma$; 2) IL-18R is expressed on murine T1, but not T2 clones; and 3) IL-18 and IL-12 regulate each others' responses [9, 10]. Administration of IL-18 enhances resistance to certain intracellular pathogens including Salmonella typhimurium and $C$. neoformans, probably by enhancing production of IFN- $\gamma$ by NK and T-cells [11]. IL-18 knockout (KO) mice infected with Mycobacterium tuberculosis or $M$. bovis develop large granulomatous lesions associated with defective IFN- $\gamma$ responses $[12,13]$. Conflicting findings regarding a role for IL-18 in L. major have been reported.

\section{Development of a specific immune response to Cryptococcus neoformans}

The entire sequence of events involved in the development of specific pulmonary immune responses can be studied in vivo utilizing animal models. This review will concentrate on the immune response to C. neoformans, an important cause of mortality in patients with acquired immune deficiency syndrome (AIDS).

Genetic susceptibility to pulmonary Cryptococcus neoformans infection

Two patterns of host resistance emerge following intratracheal inoculation of $C$. neoformans-52; $\mathrm{CBA} / \mathrm{J}$ mice are resistant, whereas $\mathrm{C} 57 \mathrm{BL} / 6$ mice are susceptible. Resistant mice progressively clear a pulmonary $C$. neoformans infection once cell-mediated immunity develops, while susceptible mice do not clear the infection. There is no difference in the magnitude of leukocyte recruitment to explain the different responses in $\mathrm{C} 57 \mathrm{BL} / 6$ and $\mathrm{CBA} / \mathrm{J}$ mice. However, the types of leukocytes recruited are markedly different. C57BL/6 mice develop a striking chronic eosinophilia in their lungs in contrast to CBA/J mice, which have fewer eosinophils at all time points [14]. In addition, C57BL/6 mice generate large amounts of $\mathrm{IgE}$ in response to $C$. neoformans, whereas CBA/J mice have no detectable IgE in their sera. Cytokine messenger ribonucleic acid (mRNA) profiles in the two strains of mice are strongly polarized by day 35 of the infection. CBA/J mice have high levels of IFN- $\gamma$ and IL-12 mRNA, low levels of IL-4 and IL-10 mRNA, and below detectable levels of IL-5 mRNA (T1 profile). In contrast, C57BL/6 mice have high levels of IL-4, IL-5 and IL-10 mRNA and below detectable levels of IFN- $\gamma$ and IL-12 mRNA (T2 profile). Thus, the immune response in resistant $\mathrm{CBA} / \mathrm{J}$ mice differentiates to a $\mathrm{T} 1$ response, while the response in susceptible $\mathrm{C} 57 \mathrm{BL} / 6$ mice differentiates to a $\mathrm{T} 2$ response.

Afferent phase production of tumour necrosis factor- $\alpha$ is required for the development of protective $T$-cell immunity to Cryptococcus neoformans

TNF- $\alpha$ is one of the first cytokines produced by macrophages or activated T-cells during nonspecific 
and Ag-specific responses. Induction of TNF- $\alpha$ in the lungs is a critical early step in the afferent phase of cell-mediated immunity against $C$. neoformans [15]. Blockade of early TNF- $\alpha$ with a single dose of antiTNF- $\alpha \mathrm{Ab}$ at the outset of a C. neoformans-52 infection results in a $10^{4}$ increase in lung microbial burden, and a $10^{5}$ increase in brain microbial burden. Delaying the induction of TNF- $\alpha$ alters the usual protective T1 response induced by $C$. neoformans -52 to a nonprotective T2 response [16]. TNF- $\alpha$-induced activation of macrophages is probably required for effective production of IL-12 by macrophages that have ingested $C$. neoformans.

Chemokines and chemokine receptors regulate $T 1$ versus $T 2$ polarization during Cryptococcus neoformans infection

Chemokines and their receptors are also importantly involved in lymphocyte differentiation. The chemokine family encompasses four structural families comprising $>50$ ligands that interact with $\geqslant 17$ different receptors [17].

The primary receptor for monocyte chemotactic peptide (MCP)-1 is CCR2. CCR2 expression is an important determinant of $\mathrm{T} 1$ versus $\mathrm{T} 2$ polarization during $C$. neoformans infections. CCR2 $+/+$ mice progressively clear a pulmonary $C$. neoformans-52 infection, while CCR2 KO mice (CCR2 -/-) are unable to clear the microbe from the lung. CCR2 -/- mice also show enhanced dissemination of $C$. neoformans to both spleen and brain.

Cytokine profiles differ markedly in $\mathrm{CCR} 2+/+$ and CCR2 -/- mice. CCR2 +/+ mice have high levels of IFN- $\gamma$, but minimal induction of IL- 4 and IL-5. The immune response in CCR2 -/- mice is characterized by chronic pulmonary eosinophilia, eosinophil-derived crystal deposition in the lungs, pulmonary leukocyte production of IL-4 and IL-5, but not IFN- $\gamma$ and increased serum IgE. Thus, expression of CCR2 is required for the development of a T1-type response to C. neoformans infection. Lack of CCR2 results in a switch to a T2 type response [18].

Macrophage inflammatory protein-1 $\alpha$ (MIP-1 $\alpha$ ), a ligand for CCR5, also plays an important role in $\mathrm{T} 1$ versus $\mathrm{T} 2$ polarization during $C$. neoformans infection. Pulmonary clearance of $C$. neoformans is significantly impaired in MIP-1 $1 \alpha$-/- mice 2 weeks after infection. The absence of MIP-1 $\alpha$ has a devastating effect on survival. Ninety per cent of MIP- $1 \alpha+/+$ animals survive to week 12 after infection, whereas only $20 \%$ of MIP- $1 \alpha-/$ mice are alive at week 12. The immune response in MIP-1 $\alpha-/-$ mice is characterized by chronic pulmonary eosinophilia, eosinophil-derived crystal deposition in the lung, destruction of lung parenchyma, enhanced IL-4 and IL-13 expression and higher levels of IgE. MIP$1 \alpha$ provides an early signal that downregulates IL-4/ IL-13 during $C$. neoformans infections, thereby preventing the development of deleterious T2 immune responses [19].
Both CD4 and CD8 T-cells are required for effective pulmonary defence against Cryptococcus neoformans

Host defences against $C$. neoformans are depen bydent on CD4+ and CD8+ T-cells. Depletion of either CD4+ T-cells or CD8+ T-cells results in impaired pulmonary clearance, earlier dissemination of $C$. neoformans from the lungs and decreased sur vival. Cellular recruitment of macrophages to the lung is significantly reduced in both CD4+ and CD8+ Tcell deficient mice. The depletion of both CD4+ and CD8+ T-cells completely abrogates macrophage recruitment to the lung and pulmonary clearance [20-22].

The recruitment of monocytes to the lung during $C$. neoformans infection is dependent on a functional network of multiple chemokines. MCP-1 plays an important role in the initial recruitment of cells (CD4+ and CD8+ T-lymphocytes and a small number of monocytes) that produce MIP- $1 \alpha$. In turn, MIP- $1 \alpha$ mediates the bulk of monocyte recruitment into the lungs [23, 24].

\section{T-cell expansion and differentiation leads to the generation of effector cells}

The functions of T-effector cells are diverse. Several broad statements can be made regarding T-effector cells. First, the kinetics of induction of T-effector cell function is seconds or minutes, versus hours or days for induction of resting T-cells. T-effector cell function involves the binding of the T-cell receptor (TCR) from the T-effector cell to peptide-MHC complexes on the target cell to unleash the signal. T-effector cells are usually released quickly from the target cell and can participate in multiple hits. Secondly, T-effector cells are more sensitive than naïve cells. T-effector cells respond to much lower concentrations of peptideMHC and are less dependent on adhesion molecules. T-effector cells are also no longer highly dependent on costimulation. Thirdly, T-effector cell functions are usually exerted on cells that present Ags (B-cells, macrophages, and virus-infected cells); however, effector T-cells are also able to kill some fungal and parasitic cells directly. Fourthly, T-effector cells use two broad types of molecular interactions to influence target cells. T-effector cell membrane bound molecules can trigger a specific ligand on target cells. T-effector cell membrane bound molecules are TNF protein family members and the target cell ligands are tumour necrosis factor receptor (TNFR)-like molecules. Alternatively, T-effector cells release soluble mediators into the immunological synapse formed at the point of T-effector cell-target cell contact. Mediators are "squirted" directly at the target cell. In both instances, the effector message is directed specifically at the target cell. This focused mediator action restricts the effects to the relevant target cells with only limited action on bystander cells.

T1 cells stimulate Ag-bearing macrophages to increase their microbicidal, cytocidal and inflammatory capacities. Soluble mediators crucial to pulmonary host defence are IFN- $\gamma$, GM-CSF, TNF- $\alpha$ 
and TNF- $\beta$. Contact-dependent signals come from membrane-bound TNF. TNF and IFN- $\gamma$ signals synergize to induce an activated state in the macrophage resulting in increased MHC molecule expression, nitric oxide/oxygen radical production, and microbicidal activity [25].

\section{$\gamma \delta$ T-cells and infection}

\section{Ontogeny of $\gamma \delta T$-cells}

During murine foetal thymic ontogeny, the first wave of T-cells are $\gamma \delta$ T-cells expressing the $\mathrm{V} \gamma 3 \mathrm{~V} \delta 1$ TCR complex (reviewed in [26]). These T-cells appear between days 13-14 of foetal gestation and migrate exclusively to the skin epidermis. Approximately 2 days later, a second wave of $\gamma \delta$ T-cells appear that express the $\mathrm{V} \gamma 3 \mathrm{~V} \delta 1$ TCR complex. The $\gamma \delta$ T-cells generated in this second wave colonize mucosal epithelium of the lung, uterus, vagina, and tongue. Unlike $\mathrm{V} \delta 3$ expressing $\gamma \delta \mathrm{T}$-cells, $\mathrm{V} \gamma 4$ bearing $\gamma \delta \mathrm{T}$-cells are not confined to the mucosal sites that they colonize during ontogeny. Shortly after the second wave of $\gamma \delta$ T-cells, $\gamma \delta$ T-cells bearing more diverse TCR combinations begin to appear. These adult $\gamma \delta$ T-cells utilize several distinct $\mathrm{V} \gamma$ and $\mathrm{V} \delta$ chains, generating increased diversity at the level of the TCR complex. Interestingly, thymic T-cell progenitors capable of generating foetal $\mathrm{V} \gamma 3$ and $\mathrm{V} \gamma 4$ expressing T-cells are present only during foetal development and require the foetal thymic microenvironment for the maturation of these specific $\gamma \delta$ T-cells subsets.

\section{Antigen recognition by $\gamma \delta T$-cells}

After their initial discovery, it was assumed that $\gamma \delta$ T-cells recognized Ag in a manner similar to that of $\alpha \beta$ T-cells. However, after years of study, this hypothesis has been largely disproved. It remains highly controversial whether $\gamma \delta$ T-cells undergo thymic selection mechanisms, as do $\alpha \beta$ T-cells. Mice deficient in $\beta 2$-microglobulin lack MHC class I expression and, therefore, lack CD8 $+\alpha \beta$ T-cells, yet have normal $\gamma \delta$ T-cell distribution. Also, MHC class I and class II double KO mice have normal splenic $\gamma \delta$ T-cells.

Unlike $\mathrm{Ag}$ recognition by $\alpha \beta \mathrm{T}$-cells, $\gamma \delta \mathrm{T}$-cell recognition does not require $\mathrm{Ag}$ processing and is not MHC-restricted (reviewed in [27]). Analyses of the heterogeneity within the complementary determining region-3 (CDR3) of $\gamma$ and $\delta$ TCR chains indicate that they resemble immunoglobulin chains more than $\alpha$ and $\beta$ TCR chains [28]. This suggests that $\gamma \delta$ T-cells recognize Ag in a manner similar to immunoglobulins (i.e. soluble and/or unprocessed $\mathrm{Ag}$ ). With this in mind, determining specific $\mathrm{Ag}$ recognition by $\gamma \delta$ T-cells during pathogenic challenge has been difficult. As predicted from CDR3 analyses, soluble Ags capable of activating $\gamma \delta$ T-cells in vitro have been identified. These include tetanus toxoid, mycobacterial heat shock protein 60 (hsp60), Staphylococcus enterotoxin A, and lipopolysaccharide (LPS). Few Ag-specific $\gamma \delta$ T-cells have been identified to date.
Clones of $\gamma \delta$ T-cells have been generated that recognize nonclassical MHC class $\mathrm{Ib}$ molecules. Interestingly, this recognition is independent of $\mathrm{Ag}$ processing. Unlike most $\gamma \delta \mathrm{T}$-cells, these class $\mathrm{Ib}$ specific cells require $\beta 2$-microglobulin and MHC class I expression. $\gamma \delta \mathrm{T}$-cells have also been reported to interact with CD1, Herpes Simplex viral glycoproteins, nonpeptide Ags, and stress or heat shockinduced proteins, in particular hsp60 [29-31]. Of these, $\gamma \delta$ T-cell recognition of hsp60 is the best defined and may be the most relevant activational pathway during bacterial infections (fig. 1).

Hsp are a family of proteins that are highly conserved across phylogeny and grouped according to molecular weight [32]. These proteins normally function as protein chaperones during protein synthesis, folding, and transport. In this regard, hsp resemble MHC molecules in that they can bind other proteins and peptides. Members of the hsp60 family, normally expressed in cytoplasmic organelles, have been shown to translocate to the cell surface during cellular stress or infection [33]. $\gamma \delta$ T-cell hybridomas have been generated that are specific for mycobacteria-derived hsp60 [34]. Further analyses indicated cross-reactivity of these T-cell clones with endogenous (murine) hsp60 [35]. A direct correlation between hsp60 expression and $\gamma \delta$ T-cell recruitment and activation has been observed. Hsp60 has been shown to activate $\gamma \delta$ Tcells, resulting in proliferation and cytokine production. This activation was cell contact dependent, TCR dependent, but MHC independent. Importantly for innate host defences, macrophages derived from pathogen infected animals have been shown to express hsp60. Moreover, macrophage upregulation of hsp60 correlates with $\gamma \delta$ T-cell recruitment and activation [36]. Recently, hsp60 has been shown to activate macrophages in vitro resulting in production of proinflammatory cytokines critical during pathogenic challenge, suggesting that infected cells expressing hsp60 can directly activate resident macrophages, thus initiating host defence mechanisms, including $\gamma \delta$ T-cell activation [37].

\section{Cytokine production by $\gamma \delta$ T-cells}

$\alpha \beta$ T-cell-mediated immunity has been classically defined in recent years according to the profile of cytokines produced and the corresponding immune response generated [38]. T-helper 1 (Th1) T-cells produce IL-2, IL-12 and IFN- $\gamma$, but not IL-4, IL-5 or IL-10. Th1 responses result in cell-mediated immunity, such as delayed-type hypersensitivity and macrophage activation. In contrast, Th2 T-cells produce IL-4, IL-5 and IL-10, but not IL-2, IL-12 or IFN- $\gamma$. The resultant immune response promotes humoral immune responses.

Recent studies indicate that $\gamma \delta$ T-cell clones can also be segregated into "T1" or "T2" classifications, with a bias towards production of T1 cytokines [39]. The biased IFN- $\gamma$ production by $\gamma \delta$ T-cells is probably due to the continued expression of the IL-12R $\beta_{2}$ chain even in the presence of IL-4, thus preserving IL-12 responsiveness in a T2 cytokine milieu [40]. $\gamma \delta$ T-cells 
have been shown to produce a wide variety of cytokines following activation $[41,42]$. Interestingly, $\gamma \delta$ $\mathrm{T}$-cells have been reported to discriminate between a T1-inducing pathogen (Listeria) and a T2 pathogen (Nippostrongylus), resulting in differential production of IFN- $\gamma$ and IL-4, respectively [43]. Other studies have suggested a link between $\gamma \delta$ T-cells and the production of TNF- $\alpha$ and IFN- $\gamma$. Macrophages from $\gamma \delta$ T-cell KO mice display impaired TNF- $\alpha$ production when stimulated with LPS in vitro [44]. Pre-incubation of these macrophages with wild-type $\gamma \delta$ T-cells restored LPS-induced TNF- $\alpha$ production. This priming activity of $\gamma \delta$ T-cells was partially inhibited by anti-IFN- $\gamma$ Abs, suggesting that $\gamma \delta$ T-cell derived IFN- $\gamma$ was required for optimal TNF- $\alpha$ secretion by macrophages challenged with LPS in vitro (and possibly Gram-negative bacteria in vivo). Similar findings were seen in an in vivo model of $S$. choleraesuis sepsis [45]. In a model of Listerosis, IFN- $\gamma$ production by NK cells was shown to be markedly reduced in $\gamma \delta$ T-cell-deficient animals [46]. Spleen cells harvested from infected $\gamma \delta$ T-cell-deficient animals displayed impaired early $\mathrm{TNF}-\alpha$ production following in vitro stimulation (summarized in fig. 1).

\section{Role of $\gamma \delta T$-cells during infection}

An emerging field of interest is the interaction between cells of the innate and acquired immune response during pathogenic insult [47]. Effective pulmonary host defences require the rapid clearance of invading bacteria from the respiratory tract. Innate immunity within the alveolus primarily consists of three types of phagocytic cells; resident alveolar macrophages, recruited neutrophils, and recruited monocytes. Along with their direct phagocytic and microbicidal capacity, these cells produce a complex network of both pro- (TNF- $\alpha$, IL-12) and antiinflammatory (IL-10) cytokines important for the recruitment and activation of inflammatory cells that ultimately clear the infection. While these innate phagocytic host responses toward bacterial infections have been well characterized, less is known about $\mathrm{T}$-cells and their role during these infections, and in particular the role of $\gamma \delta$ T-cells.

To study the role of specific T-cell populations in Gram-negative bacterial pneumonia, the present authors utilized mice deleted of their TCR $\beta$ and/or $\delta$ chain by homologous recombination and which were intratracheally inoculated with Klebsiella pneumoniae [48]. Mice specifically lacking $\gamma \delta$ T-cells had increased susceptibility to pulmonary bacterial challenge when compared to $\alpha \beta$ T-cell KO and wild-type mice. The $\gamma \delta$ $\mathrm{KO}$ mice had significantly impaired early expression of pulmonary and hepatic IFN- $\gamma$ and TNF- $\alpha$ mRNA following $K$. pneumoniae infection, increased peripheral blood bacterial dissemination, and increased hepatic bacterial burden subsequent to the initial pulmonary infection. The data suggested that $\gamma \delta$ T-cell KO mice succumb due to an impaired ability to clear disseminated bacteria from the bloodstream and liver, rather than an inability to clear the organism from the primary site of infection in the lung. A recent study of nocardial pneumonia in $\gamma \delta \mathrm{T}$ cell KO mice confirmed the importance of $\gamma \delta$ T-cells in the clearance of pulmonary pathogens [49]. The $\gamma \delta \mathrm{T}$ cell $\mathrm{KO}$ mice had unimpeded bacterial growth that correlated with a dramatic increase in mortality. In contrast, pneumonia models using Pneumocystis carinii, $M$. tuberculosis, or $M$. avium reported no detrimental effects in the absence of $\gamma \delta$ T-cells [50-52], suggesting a differential requirement for $\gamma \delta \mathrm{T}$-cells depending on the pathogenic organism studied.

As with pulmonary infection models, conflicting data exist regarding the importance of $\gamma \delta$ T-cells during systemic pathogenic infections. A protective role for $\gamma \delta$ T-cells has been shown in several models of systemic bacterial infections, particularly in the setting of intracellular pathogens such as Toxoplasma [53] and Listeria [46]. In an intraperitoneal sepsis model using Escherichia coli, mice lacking $\gamma \delta$ T-cells were more susceptible to infection. Interestingly, decreased neutrophil and macrophage recruitment into the site of infection was observed, which correlated with increased bacterial burden, suggesting a role for $\gamma \delta$ $\mathrm{T}$-cells in effector cell recruitment [54]. Furthermore, the recent observation that $\gamma \delta$ T-cells are preferentially stimulated early after in vivo systemic bacterial or LPS inoculation, in contrast to $\alpha \beta$ T-cells, suggests that $\gamma \delta$ T-cells may be responsible for rapid cytokine production immediately following pathogenic challenge [55]. However, other studies suggest a detrimental role for $\gamma \delta$ T-cells during sepsis. Intraperitoneal infection of $\gamma \delta$ T-cell KO mice with $S$. choleraesuis resulted in significantly improved survival when compared to wild-type infected animals [45]. This improved survival was attributed to decreased serum levels of TNF- $\alpha$. Another study using $S$. choleraesuis infected $\gamma \delta$ T-cell $\mathrm{KO}$ mice indicated reduced liver injury in the absence of $\gamma \delta$ T-cells; however, no detrimental effects on bacterial clearance were noted [56]. To further complicate the picture, two recent reports indicate that in vivo depletion of $\mathrm{V} \gamma 1$ or $\mathrm{V} \gamma 4$ expressing $\gamma \delta \mathrm{T}$-cell subsets has beneficial or detrimental effects following infection, depending on the pathogen studied [57, 58]. Growing evidence suggests that $\gamma \delta$ T-cells, while possibly not playing a critical role in the early clearance of bacterial insult, may play an important immunoregulatory role later during the infection (reviewed in [59]). In both Listeria and Mycobacterium infections, infectious lesions or foci develop, which are initially rich in infiltrating neutrophils. In wild-type mice, an orderly replacement of neutrophils with a mononuclear cell infiltrate occurs within several days. In mice deficient in $\gamma \delta$ T-cells, this mononuclear cell replacement is disrupted and delayed, resulting in increased localized tissue damage.

\section{B-cells and infection}

\section{B-cell activation}

Humoral immunity within the lung refers to $\mathrm{Ab}$-mediated protective immune responses. B-cells 
are the Ab-producing cells of the immune system. A mature B-cell is activated when it encounters Ag that expresses epitopes that are recognized by surface Ig. The activation process may involve the direct crosslinking of surface Ig in a process called T-independent activation, so named because the B-cells are directly activated without additional signals delivered by immune T-cells [60]. T-independent Ags are highly repetitious structures and are generally components of bacterial cell walls (e.g. LPS, lipoproteins, pneumococcal polysaccharide, proteoglycan, and porin). T-independent immune responses are a major protective immune response generated against encapsulated microbes.

$\mathrm{Ab}$ responses to most complex Ags, including protein Ags, are dependent on T-cell help. T-cell help is generated in the form of direct B-cell to T-cell contacts and the release of activating cytokines. Full activation of a T-dependent immune response requires a complex interplay between $\mathrm{Ag}$ presenting cells (APC), Ag, B-cells, and T-cells (fig. 1). The typical activation scenario involves the phagocytosis of foreign Ag by an APC (typically dendritic cells or macrophages). The APC then processes the protein portions of the Ag into small peptide fragments, and re-expresses these peptide fragments on the surface of the APC in association with major MHC molecules. The complex of the Ag peptide and the MHC molecule can be recognized by the TCR on the surface of the Th cells. Th cells recognize peptide $\mathrm{Ag}$ in the context of MHC class II molecules. Once the TCR has bound to the MHC class II-peptide Ag complex on the APC, a second binding event takes place whereby the CD4 molecule on the Th cell binds to the MHC class II molecule. This is referred to as costimulation and results in additional activation signals within the $\mathrm{Th}$ cell. Now the Th cell expresses a new molecule on its cell surface known as CD40 ligand (CD40L). The CD40L can now bind to the CD40 molecule on B-cells. The ligation of CD40 on B-cells by CD40L on Th cells results in an activation cascade within the B-cell, resulting in expression of cytokine receptors on the B-cell. Activated Th cells are secreting cytokines that can now bind to and fully activate the production of Ig by the B-cells [61, 62].

The cytokine cascade that is generated between $\mathrm{Th}$ and B-cells varies depending on the nature of the Ag encountered. These cytokine signals induce B-cells to proliferate and to terminally differentiate into $\mathrm{Ab}$ forming plasma cells. This response leads to the initial wave of IgM production. Subsequently, B-cells can further differentiate into effector cells secreting a different $\operatorname{Ig}$ isotype ( $\mathrm{IgG}, \operatorname{IgA}$ or $\mathrm{IgE}$ ) or can become memory cells. The circulating memory cells are largely responsible for the rapid recognition (immunological memory) and effective immune elimination of organisms that have previously invaded the host [63].

\section{Immunoglobulin isotypes}

Ig isotypes can be divided into five major subclasses of Ab: IgM, IgD, IgG, IgA and IgE. The effector function of each isotype results from the interactions between the heavy-chain constant region $(\mathrm{Fc})$ and other serum proteins or cell membrane receptors [61].

$\mathrm{IgG}$ is the most abundant isotype in serum and constitutes $\sim 80 \%$ of the total serum Ig. Human $\mathrm{IgG}$ exists as four different isotypes, named in accordance with their decreasing average serum concentrations: $\operatorname{IgG} 1\left(9 \mathrm{mg} \cdot \mathrm{mL}^{-1}\right), \operatorname{IgG} 2\left(3 \mathrm{mg} \cdot \mathrm{mL}^{-1}\right), \operatorname{IgG} 3$ $\left(1 \mathrm{mg} \cdot \mathrm{mL}^{-1}\right)$ and $\mathrm{IgG} 4\left(0.5 \mathrm{mg} \cdot \mathrm{mL}^{-1}\right)$ with slightly different biological functions. IgG1, IgG3, and $\mathrm{IgG} 4$ readily cross the placenta. IgG3 and $\mathrm{IgG} 1$ are also potent activators of the complement system, whereas IgG2 only weakly activates the complement system, and IgG4 is unable to activate this system at all. IgG1 and $\mathrm{IgG} 3$ bind Fc receptors and are efficient opsonins [64]. IgG is most often found in the lower respiratory tract [65], and patients with primary or secondary IgG deficiencies suffer from infections caused by encapsulated micro-organisms, such as Hemophilus influenzae and Staphylococcus pneumoniae.

IgM accounts for $5-10 \%$ of the total serum Ig concentration with an average concentration of $1.5 \mathrm{mg} \cdot \mathrm{mL}^{-1}$. Monomeric IgM is expressed on the cell surface, while secreted IgM is found as a pentamer of monomeric IgM molecules. IgM is the first Ig to be produced during an immune response, and is an excellent agglutinin. IgM efficiently activates the complement system, but has limited diffusion capacity into tissues because of its large size. IgM can be actively transported across epithelial linings and is found at low levels in the external secretions that bathe mucous membranes [64].

IgA only constitutes $10-15 \%$ of the total serum Ig, but is the predominant Ig class found in external secretions and the mucous membranes of the bronchial, digestive, and genitourinary tracts. In serum, IgA exists as a monomer, but in secretions, IgA is found as a dimer or tetramer. In addition, secretory IgA has an additional polypeptide component known as secretory component that binds to IgA and masks sites susceptible to proteolytic digestion. This keeps the IgA intact and active in the protease-rich mucosal environment [66]. IgA has been shown to be important in host defences in response to pathogens such as Salmonella, Vibrio cholerae, Neisseria gonorrhea and viruses such as polio and influenza. In humans, IgA can be found as two isotypes: $\operatorname{IgA} 1$ $\left(3 \mathrm{mg} \cdot \mathrm{mL}^{-1}\right)$ and $\operatorname{IgA} 2\left(0.5 \mathrm{mg} \cdot \mathrm{mL}^{-1}\right)$. Within the lung, $\operatorname{IgA}$ is most abundant on the mucosa of the upper airways. Classical induction of a protective $\operatorname{IgA}$ $\mathrm{Ab}$ response is likely to involve immunization via a mucosal route $[61,65]$.

$\operatorname{IgE} \mathrm{Abs}$ are present at very low concentrations in serum $\left(0.3 \mu \mathrm{g} \cdot \mathrm{mL}^{-1}\right)$, but are responsible for potent biological effects associated with hypersensitivity reactions, such as hay fever, asthma, hives and anaphylaxis. $\mathrm{IgE}$ binds to $\mathrm{Fc}$ receptors on membranes of basophils and mast cells. When Ags (allergens) bind to $\mathrm{IgE}$ bound to mast cells and basophils, these cells respond by degranulating and releasing potent biological mediators, such as histamine. IgE is an important immune defence against some parasitic pathogens $[61,65]$.

$\operatorname{IgD}$ is generally only found on the surface of mature B-cells. It may play a role in B-cell activation 
or homing, but is rarely secreted. IgD is lost from B-cells following Ag activation [61, 67].

\section{Antibody effector functions}

Abs participate in host defence by a variety of effector functions. These effector functions include opsonization, complement fixation, Ab-dependent cellular cytotoxicity (ADCC), agglutination and neutralization. Opsonization involves the recognition of cell surface Ags on pathogens and binding by $\mathrm{Ab}$ molecules. Binding of the $\mathrm{Ab}$ to the pathogen exposes the $\mathrm{Fc}$ portion of the $\mathrm{Ab}$ to effector cells that are nearby. Fc binding brings effector macrophages in close proximity to the pathogen and increases the rate and efficiency of phagocytosis of the pathogen, facilitating elimination.

The complement fixation system consists of nearly 30 serum- and membrane-bound proteins synthesized by hepatocytes and also by some blood monocytes. Binding of two Ig molecules within close proximity of each other on the surface of a pathogen can cause the activation (fixation) of the complement system. This activation sets off a cascade of events that eventually result in the formation of a "membrane attack complex" on the surface where the original Igs were deposited. This "membrane attack complex" serves to rupture the membrane of the invading pathogen, thereby eliminating the organism [68].

$\mathrm{ADCC}$ is a process in which $\mathrm{Ab}$ serves as a bridge to join infected host cells (recognized by the surface expression of viral or bacterial Ags) with effector cells, including neutrophils, macrophages, NK cells and eosinophils. These effector cells act to eliminate the infected host cells by secreting lytic enzymes and granules that will result in membrane damage and lysis of the infected cell [69].

Agglutination is the process whereby secreted $\mathrm{Ab}$ binds to foreign $\mathrm{Ag}$ in such a way that extensive Ag-Ab crosslinking is established. A large, often insoluble complex is formed, which becomes a target to be cleared via complement fixation, ADCC, and reticuloendothelial filtration. Furthermore, steric hindrance imposed by the extensive $\mathrm{Ab}$ crosslinking may serve to hinder the ability of the pathogen to infect host cells. Within the lung, agglutination is an important antiviral defense mechanism. Similarly, secreted Abs can bind to bacterial toxins and thus, neutralize the biological activity of the toxin.

\section{Humoral immunity within the lung}

Pulmonary $\mathrm{Ab}$ responses have been evaluated in a number of model systems. Pulmonary Ag exposure results in generation of Ag-specific B-cells within the lung and draining lymph nodes. Following Ag exposure, long-lived memory B-cells may reside within the localized areas of the lung where the initial insult was encountered [70]. Ag-specific Abs may also arrive in the lung via transudation from the blood. Ab transudation increases during inflammatory reactions when the vascular permeability is increased. Experimental systems have demonstrated a beneficial role for $\mathrm{Ab}$ in response to pulmonary infection. For example, passive administration of opsonic IgG monoclonal$\mathrm{Ab}$ directed against nontypeable $H$. influenzae lipooligosaccharide results in enhanced pulmonary clearance of the organism [71]. Similarly, peripheral immunization can protect against $H$. influenzae [71]. Serum Abs serve to increase the phagocytosis of microbes both in vitro and in vivo, effectively increasing host resistance [72].

Humoral immunity can also play a role in fungal infections, such as the facultative intracellular pathogen $C$. neoformans. $C$. neoformans is unusual in that it has an antiphagocytic polysaccharide capsule that is shed during infection. C. neoformans infection generates Abs against a variety of Ags, including glucuronoxylomannan (GXM) and galacoxylomannan. Abs against GXM can be protective against a lethal dose of $C$. neoformans in animal studies. Furthermore, individuals with defects in humoral immunity are more susceptible to $C$. neoformans infection, even though T-cell-mediated immunity is thought to be the primary host immune defence against this organism. Protective $\mathrm{Ab}$ responses are associated with complement activation, enhanced phagocytosis by macrophages, neutrophils, microglia, eosinophils, and peripheral blood mononuclear cells. In addition, Abs interfere with $C$. neoformans adhesion to human cells, and agglutinate and remove shed polysaccharide Ag from serum. Finally, the presence of protective $\mathrm{Abs}$ has been shown to influence the cytokine production in response to C. neoformans, suggesting that there may be more interplay between the humoral and cell-mediated branches of the immune system than was previously recognized [73, 74].

One final comment about humoral immunity is that the formation of protective antibody responses is diminished in older individuals, causing significant problems in the lung because respiratory infections are common and result in significant morbidity and mortality in the aged population. Evidence suggests that older mice tend to use different variable region genes in response to bacterial challenge, which result in less avid and less protective immune responses [75]. Furthermore, the somatic mutation frequency may be lower in aged B-cells, thus limiting the generation of antibodies of higher affinity [76]. As a result, there is considerable interest in manipulating the immune response in aged populations to increase the likelihood of protective immunity developing to potentially devastating infections like pneumococcus. For this reason, the Public Health Service adult immunization goals for the year 2000 state that $60 \%$ of all elderly and high-risk individuals should receive the 23-valent pneumococcal and influenza vaccines [77]. The wealth of animal data supporting stronger, higher affinity antibody generation in younger animals raise the possibility that recommendations should be modified to immunize patients prior to age 65 . In fact, the administration of the 23 -valent pneumococcal vaccine in the presence of adjuvant has been shown to result in the development of immunoglobulin-G 
and immunoglobulin-A responses, rather than the usual immunoglobulin-M response seen with most polysaccharide immunizations [78, 79]. Immunoglobulin-G and immunoglobulin-A responses could have the advantage of being more specific and allowing different effector clearance mechanisms. Therefore, future studies may generate recommendations for immunization protocols that will be more advantageous to older adults.

\section{References}

1. Abbas AK, Murphy KM, Sher A. Functional diversity of helper T lymphocytes. Nature 1996; 383: 787 793.

2. Mosmann TR, Coffman RL. TH1 and TH2 cells: different patterns of lymphokine secretion lead to different functional properties. Annu Rev Immunol 1989; 7: 145-173.

3. Hsieh CS, Macatonia SE, Tripp CS, Wolf SF, O'Garra A, Murphy KM. Development of TH1 CD4+ $\mathrm{T}$ cells through IL-12 produced by Listeriainduced macrophages. Science 1993; 260: 547-549.

4. Macatonia SE, Hosken NA, Litton M, et al. Dendritic cells produce IL-12 and direct the development of Th1 cells from naive CD4+ T cells. J Immunol 1995; 154: 5071-5079.

5. Kaplan MH, Grusby MJ. Regulation of $\mathrm{T}$ helper cell differentiation by STAT molecules. J Leukoc Biol 1998; 64: 2-5.

6. O'Garra A. Cytokines induce the development of functionally heterogeneous $\mathrm{T}$ helper cell subsets. Immunity 1998; 8: 275-283.

7. Szabo SJ, Dighe AS, Gubler U, Murphy KM. Regulation of the interleukin (IL)-12R beta 2 subunit expression in developing $\mathrm{T}$ helper 1 (Th1) and $\mathrm{Th} 2$ cells. J Exp Med 1997; 185: 817-824.

8. Robinson D, Shibuya K, Mui A, et al. IGIF does not drive Th1 development but synergizes with IL-12 for interferon-gamma production and activates IRAK and NFkappaB. Immunity 1997; 7: 571-581.

9. $\mathrm{Xu} \mathrm{D,} \mathrm{Chan} \mathrm{WL,} \mathrm{Leung} \mathrm{BP,} \mathrm{et} \mathrm{al.} \mathrm{Selective} \mathrm{expression}$ and functions of interleukin 18 receptor on T helper (Th) type 1 but not Th2 cells. J Exp Med 1998; 188: 1485-1492.

10. Yoshimoto $\mathrm{T}$, Takeda $\mathrm{K}$, Tanaka $\mathrm{T}$, et al. IL-12 up-regulates IL-18 receptor expression on T cells, Th1 cells, and B cells: synergism with IL-18 for IFN-gamma production. J Immunol 1998; 161: 3400 3407.

11. Qureshi MH, Zhang T, Koguchi Y, et al. Combined effects of IL-12 and IL-18 on the clinical course and local cytokine production in murine pulmonary infection with Cryptococcus neoformans. Eur J Immunol 1999; 29: 643-649.

12. Sugawara I, Yamada $\mathrm{H}$, Kaneko $\mathrm{H}$, Mizuno $\mathrm{S}$, Takeda K, Akira S. Role of interleukin-18 (IL-18) in mycobacterial infection in IL-18-gene-disrupted mice. Infect Immun 1999; 67: 2585-2589.

13. Takeda K, Tsutsui H, Yoshimoto $\mathrm{T}$, et al. Defective NK cell activity and Th1 response in IL-18-deficient mice. Immunity 1998; 8: 383-390.

14. Huffnagle GB, Boyd MB, Street NE, Lipscomb MF. IL-5 is required for eosinophil recruitment, crystal deposition, and mononuclear cell recruitment during a pulmonary Cryptococcus neoformans infection in genetically susceptible mice (C57BL/6). J Immunol 1998; 160: 2393-2400.

15. Huffnagle GB, Chen GH, Curtis JL, McDonald RA, Strieter RM, Toews GB. Down-regulation of the afferent phase of $\mathrm{T}$ cell-mediated pulmonary inflammation and immunity by a high melanin-producing strain of Cryptococcus neoformans. J Immunol 1995; 155: $3507-3516$.

16. Huffnagle GB, Toews GB, Burdick MD, et al. Afferent phase production of TNF-alpha is required for the development of protective $\mathrm{T}$ cell immunity to Cryptococcus neoformans. J Immunol 1996; 157: 45294536.

17. Kunkel SL. Through the looking glass: the diverse in vivo activities of chemokines. J Clin Invest 1999; 104 : 1333-1334.

18. Traynor TR, Kuziel WA, Toews GB, Huffnagle GB. CCR2 expression determines T1 versus $\mathrm{T} 2$ polarization during pulmonary Cryptococcus neoformans infection. J Immunol 2000; 164: 2021-2027.

19. Olszewski MA, Huffnagle GB, McDonald RA, et al. The role of macrophage inflammatory protein-1alpha/ CCL3 in regulation of $\mathrm{T}$ cell-mediated immunity to Cryptococcus neoformans infection. J Immunol 2000; 165: 6429-6436.

20. Huffnagle GB, Yates JL, Lipscomb MF. Immunity to a pulmonary Cryptococcus neoformans infection requires both CD4+ and CD8+ T cells. J Exp Med 1991; 173: 793-800.

21. Mody CH, Chen GH, Jackson C, Curtis JL, Toews GB. Depletion of murine $\mathrm{CD} 8+\mathrm{T}$ cells in vivo decreases pulmonary clearance of a moderately virulent strain of Cryptococcus neoformans. J Lab Clin Med 1993; 121: 765-773.

22. Mody CH, Lipscomb MF, Street NE, Toews GB. Depletion of CD4+ (L3T4+) lymphocytes in vivo impairs murine host defense to Cryptococcus neoformans. J Immunol 1990; 144: 1472-1477.

23. Huffnagle GB, Strieter RM, McNeil LK, et al. Macrophage inflammatory protein-1alpha (MIPlalpha) is required for the efferent phase of pulmonary cell-mediated immunity to a Cryptococcus neoformans infection. J Immunol 1997; 159: 318-327.

24. Huffnagle GB, Strieter RM, Standiford TJ, et al. The role of monocyte chemotactic protein-1 (MCP-1) in the recruitment of monocytes and CD4+ T cells during a pulmonary Cryptococcus neoformans infection. J Immunol 1995; 155: 4790-4797.

25. Kaufmann SH. Immunity to intracellular bacteria. Annu Rev Immunol 1993; 11: 129-163.

26. Born W, Cady C, Jones-Carson J, Mukasa A, Lahn M, O'Brien R. Immunoregulatory functions of gamma delta T cells. Adv Immunol 1999; 71: 77-144.

27. Chien YH, Jores R, Crowley MP. Recognition by gamma/delta T cells. Annu Rev Immunol 1996; 14: 511-532.

28. Rock EP, Sibbald PR, Davis MM, Chien YH. CDR3 length in antigen-specific immune receptors. $J$ Exp Med 1994; 179: 323-328.

29. Spada FM, Grant EP, Peters PJ, et al. Self-recognition of CD1 by gamma/delta T cells: implications for innate immunity. J Exp Med 2000; 191: 937-948.

30. Crowley MP, Fahrer AM, Baumgarth N, et al. A population of murine gammadelta $\mathrm{T}$ cells that recognize an inducible MHC class Ib molecule. Science 2000; 287: 314-316. 
31. Reardon CL, Born W, O'Brien RL. Murine gamma delta $T$ lymphocyte recognition of HSP-60: a possible source for bacterial immunity or autoimmunity. Chem Immunol 1992; 53: 121-128.

32. Jaattela M. Heat shock proteins as cellular lifeguards. Ann Med 1999; 31: 261-271.

33. Belles C, Kuhl A, Nosheny R, Carding SR. Plasma membrane expression of heat shock protein 60 in vivo in response to infection. Infect Immun 1999; 67: 41914200.

34. O'Brien RL, Happ MP, Dallas A, et al. Recognition of a single hsp-60 epitope by an entire subset of gamma delta T lymphocytes. Immunol Rev 1991; 121: 155-170.

35. Rajasekar R, Sim GK, Augustin A. Self heat shock and gamma delta T-cell reactivity. Proc Natl Acad Sci USA 1990; 87: 1767-1771.

36. Hisaeda $\mathrm{H}$, Sakai $\mathrm{T}$, Ishikawa $\mathrm{H}$, et al. Heat shock protein 65 induced by gammadelta $\mathrm{T}$ cells prevents apoptosis of macrophages and contributes to host defense in mice infected with Toxoplasma gondii. J Immunol 1997; 159: 2375-2381.

37. Chen W, Syldath U, Bellmann K, Burkart V, Kolb H. Human $60-\mathrm{kDa}$ heat-shock protein: a danger signal to the innate immune system. J Immunol 1999; 162: 3212-3219.

38. Mosmann TR, Sad S. The expanding universe of T-cell subsets: Th1, Th2 and more. Immunol Today 1996; 17: 138-146.

39. Duhindan N, Farley AJ, Humphreys S, Parker C, Rossiter B, Brooks CG. Patterns of lymphokine secretion amongst mouse gamma delta $\mathrm{T}$ cell clones. Eur J Immunol 1997; 27: 1704-1712.

40. Yin Z, Zhang DH, Welte T, et al. Dominance of IL-12 over IL-4 in gamma delta T cell differentiation leads to default production of IFN-gamma: failure to down-regulate IL-12 receptor beta 2-chain expression. J Immunol 2000; 164: 3056-3064.

41. Hsieh B, Schrenzel MD, Mulvania T, Lepper HD, DiMolfetto-Landon L, Ferrick DA. In vivo cytokine production in murine listeriosis. Evidence for immunoregulation by gamma delta+ T cells. J Immunol 1996; 156: $232-237$.

42. Skeen MJ, Ziegler HK. Activation of gamma delta $\mathrm{T}$ cells for production of IFN-gamma is mediated by bacteria via macrophage-derived cytokines IL-1 and IL-12. J Immunol 1995; 154: 5832-5841.

43. Ferrick DA, Schrenzel MD, Mulvania T, Hsieh B, Ferlin WG, Lepper H. Differential production of interferon-gamma and interleukin- 4 in response to Th1- and Th2-stimulating pathogens by gamma delta T cells in vivo. Nature 1995; 373: 255-257.

44. Nishimura H, Emoto M, Hiromatsu K, et al. The role of gamma delta $\mathrm{T}$ cells in priming macrophages to produce tumor necrosis factor-alpha. Eur J Immunol 1995; 25: 1465-1468.

45. Emoto M, Nishimura H, Sakai T, et al. Mice deficient in gamma delta $\mathrm{T}$ cells are resistant to lethal infection with Salmonella choleraesuis. Infect Immun 1995; 63: 3736-3738.

46. Ladel CH, Blum C, Kaufmann SH. Control of natural killer cell-mediated innate resistance against the intracellular pathogen Listeria monocytogenes by gamma/delta T lymphocytes. Infect Immun 1996; 64: 1744-1749.

47. Mak TW, Ferrick DA. The gammadelta T-cell bridge: linking innate and acquired immunity. Nat Med 1998; 4: 764-765.

48. Moore TA, Moore BB, Newstead MW, Standiford TJ. Gamma delta-T cells are critical for survival and early proinflammatory cytokine gene expression during murine Klebsiella pneumonia. J Immunol 2000; 165: 2643-2650.

49. King DP, Hyde DM, Jackson KA, et al. Cutting edge: protective response to pulmonary injury requires gammadelta T lymphocytes. J Immunol 1999; 162: 5033-5036.

50. D'Souza CD, Cooper AM, Frank AA, Mazzaccaro RJ, Bloom BR, Orme IM. An anti-inflammatory role for gamma delta $\mathrm{T}$ lymphocytes in acquired immunity to Mycobacterium tuberculosis. J Immunol 1997; 158: 1217-1221.

51. Saunders BM, Frank AA, Cooper AM, Orme IM. Role of gamma delta $\mathrm{T}$ cells in immunopathology of pulmonary Mycobacterium avium infection in mice. Infect Immun 1998; 66: 5508-5514.

52. Hanano R, Reifenberg K, Kaufmann SH. Naturally acquired Pneumocystis carinii pneumonia in gene disruption mutant mice: roles of distinct $\mathrm{T}$-cell populations in infection. Infect Immun 1996; 64: 32013209.

53. Kasper LH, Matsuura T, Fonseka S, Arruda J, Channon JY, Khan IA. Induction of gammadelta $\mathrm{T}$ cells during acute murine infection with Toxoplasma gondii. J Immunol 1996; 157: 5521-5527.

54. Takano M, Nishimura H, Kimura Y, et al. Protective roles of gamma delta $\mathrm{T}$ cells and interleukin-15 in Escherichia coli infection in mice. Infect Immun 1998; 66: 3270-3278.

55. Lahn M, Kalataradi H, Mittelstadt P, et al. Early preferential stimulation of gamma delta $\mathrm{T}$ cells by TNF-alpha. J Immunol 1998; 160: 5221-5230.

56. Ishigami M, Nishimura H, Yoshioka K, Kakumu S, Yoshikai Y. The role of intrahepatic gammadelta-T cells for liver injury induced by Salmonella infection in mouse. Microbiol Immunol 1999; 43: 461-469.

57. O'Brien RL, Yin X, Huber SA, Ikuta K, Born WK. Depletion of a gammadelta $T$ cell subset can increase host resistance to a bacterial infection. J Immunol 2000; 165: 6472-6479.

58. Huber SA, Graveline D, Newell MK, Born WK, $\mathrm{O}^{\prime}$ Brien RL. Vgamma1(+) $\mathrm{T}$ cells suppress and vgamma4(+) $\mathrm{T}$ cells promote susceptibility to coxsackievirus B3-induced myocarditis in mice. J Immunol 2000; 165: 41744181.

59. Carding SR, Egan PJ. The importance of gamma delta $\mathrm{T}$ cells in the resolution of pathogen-induced inflammatory immune responses. Immunol Rev 2000; 173: 98-108.

60. Ales-Martinez JE, Cuende E, Martinez C, Parkhouse RM, Pezzi L, Scott DW. Signalling in B cells. Immunol Today 1991; 12: 201-205.

61. Kuby J , ed. Immunology. 2nd Edn. New York, W.H. Freeman and Company, 1994.

62. Parker DC. T cell-dependent B cell activation. Annu Rev Immunol 1993; 11: 331-360.

63. Tonegawa S. Somatic generation of antibody diversity. Nature 1983; 302: 575-581.

64. Jefferis R, Pound J. Immunoglobulins. In: Gallin J, Goldstein I, Snyderman R, eds. Inflammation: Basic Principles and Clinical Correlates. New York, Raven Press, 1992; pp. 11-31.

65. Gerhard W, Mozdzanowska K, Furchner M, Washko 
G, Maiese K. Role of the B-cell response in recovery of mice from primary influenza virus infection. Immunol Rev 1997; 159: 95-103.

66. Neutra MR, Kraehenbuhl JP. M cell-mediated antigen transport and monoclonal IgA antibodies for mucosal immune protection. Adv Exp Med Biol 1992; 327: $143-150$.

67. Chen J, Alt FW. Gene rearrangement and B-cell development. Curr Opin Immunol 1993; 5: 194-200.

68. Frank M, Fries L. The role of complement in inflammation and phagocytosis. Immunol Today 1991; 12: 322-326.

69. Versteeg R. NK cells and T cells: mirror images? Immunol Today 1992; 13: 244-247.

70. Bice D, Gray R, Evans M, Muggenburg B. Identification of plasma cells in lung alveoli and interstitial tissues after localized lung immunization. J Leukoc Biol 1987; 41: 1-7.

71. McGehee J, Radolf J, Toews G, Hansen E. Effect of primary immunization on pulmonary clearance of nontypeable Haemophilus influenzae. Am J Respir Cell Mol Biol 1989; 1: 201-210.

72. Smith A. Hemophilus influenzae pneumonia. In: Pennington J, ed. Respiratory Infections: Diagnosis and Management. New York, Raven Press, 1994; pp. 435-454.

73. Vacchiarelli A, Casadevall A. Antibody-mediated effects against Cryptococcus neoformans: evidence for interdependency and collaboration between humoral and cellular immunity. Res Immunol 1998; 149: 321333.

74. Vecchiarelli A, Retini C, Moari C, Casadevall A. Specific antibody to Cryptococcus neoformans alters human leukocyte cytokine synthesis and promotes T-cell proliferation. Infect Immun 1998; 66: 1244-1247.

75. Riley SC, Froscher BG, Linton PJ, Zharhary D, Marcu K, Klinman NR. Altered VH gene segment utilization in the response to phosphorylcholine by aged mice. J Immunol 1989; 143: 3798-3805.

76. Yang X, Stedra J, Cerny J. Relative contribution of $\mathrm{T}$ and $\mathrm{B}$ cells to hypermutation and selection of the antibody repertoire in germinal centers of aged mice. J Exp Med 1996; 183: 959-970.

77. Centers for Disease Control Prevention. Influenza and pneumococcal vaccination coverage levels among persons aged $>$ or $=65$ years-United States, 1973-1993. MMWR Morb Mortal Wkly Rep 1995; 44: 506-507, 513-515.

78. VanCott JL, Kobayashi T, Yamamoto M, Pillai S, McGhee JR, Kiyono H. Induction of pneumococcal polysaccharide-specific mucosal immune responses by oral immunization. Vaccine 1996; 14: 392-398.

79. Garg M, Subbarao B. Immune responses of systemic and mucosal lymphoid organs to Pnu-Imune vaccine as a function of age and the efficacy of monophosphoryl lipid A as an adjuvant. Infect Immun 1992; 60: 2329-2336. 